\title{
EVOLUÇÃO DA ÁREA BASAL E DO VOLUME EM BRACATINGAIS NATIVOS SUBMETIDOS À DIFERENTES DENSIDADES INICIAIS E EM DIFERENTES SÍTIOS
}

\author{
Sebastião do Amaral Machado ${ }^{1}$ \\ Ana Elizabete N. Tonon ${ }^{2}$ \\ Afonso Figueiredo Filho ${ }^{3}$ \\ Edilson Batista Oliveira ${ }^{4}$
}

\begin{abstract}
RESUMO
Foram analisados os efeitos de quatro densidades iniciais (2, 4, 8 e 25,15 mil plantas por hectare) e de 3 classes de sítio, cujos índices de sítios são 10,2; 13,5 e 16,8 m de altura dominante aos 7 anos de idade, sobre a área basal e volume por hectare em povoamentos nativos de bracatinga (Mimosa scabrella Benth.) na região metropolitana de Curitiba. Os dados provieram de um experimento de densidades em blocos ao acaso medidos nas idades de 4,1; 5,1; 6,3 e 7,6 anos. Os efeitos da densidade inicial e do sítio sobre a área basal $(\mathrm{G})$ e volume $(\mathrm{V})$ por hectare foram verificados através de análise de variância seguida do teste de Tukey, quando pertinente. A densidade inicial de 4 mil plantas por hectare gerou maiores valores de $\mathrm{G}$ e $\mathrm{V}$ nas últimas idades de medição. A área basal/ha não sofreu efeitos significativos do sítio em nenhuma das medições, enquanto que o volume/ha foi afetado por este fator (sítio) até a idade de 6,3 anos.
\end{abstract}

Palavras-chave: Bracatinga, crescimento e produção, dinâmica

\section{EVOLUTION OF BASAL AREA AND VOLUME PER HECTARE IN NATIVE "BRACATINGAIS" SUBMITED TO DIFFERENT INITIAL DENSITIES AND DIFFERENT SITES}

\begin{abstract}
The objectives of this research were to study the effects of four initial densities $(2000,4000,8000$ and 25150 plants/ha) and three site classes (site index 10.2, 13.5 and $16.8 \mathrm{~m}$ of dominant height at age seven) on basal area $(\mathrm{G})$ and volume per hectare $(\mathrm{V})$ for native stands of bracatinga (Mimosa scabrella Benth.) in the Metropolitan Region of Curitiba, Brazil. The data set came from permanent sample plots of a density trial established in a random blocks design. These plots were measured at ages 4.1, $5.1,6.3$, and 7.6 years of age. The effects of initial density and site on basal area and volume per hectare were verified through graphics and analysis of variance followed by the Tukey test when necessary. The initial density of 4,000 plants/ha generated the highest values of basal area and volume in the last ages of measurement. The basal area/ha did not sufered significative effects of site at any one of the measurement ages, while volume/ha was affected by this factor (site) until the age of 6.3 years.
\end{abstract}

Keywords: Bracatinga, growth and yield, dynamic

\footnotetext{
${ }^{1}$ Eng. Florestal, PhD., CREA-PR 2413-D, Professor Sênior do Depto.de Ciências Florestais da UFPR, Pesquisador 1A do CNPq, Rua Pref. Lothário Meissner, 3400, Jardim Botânico, CEP 80210-170, Curitiba, PR. sammac@ floresta.ufpr.br

${ }^{2}$ Eng. Florestal, M.Sc., Curso de Pós-Graduação em Engenharia Florestal da UFPR.

${ }^{33}$ Eng.Florestal, Dr., CREA-PR 5993-D, Prof. Unicentro e Prof. Sênior do Departamento de Ciências Florestais da UFPR, Pesquisador 2A do CNPq, Rua Pref. Lothário Meissner, 3400, Jardim Botânico, CEP 80210-170, Curitiba, PR. afig@floresta.ufpr.br

${ }^{4}$ Eng. Agrônomo, Dr., CREA-AC 1211-D, Pesquisador da Embrapa Florestas, Estrada da Ribeira km 111, Caixa Postal 319, CEP 83411-000, Colombo, PR. edílson@cnpf.embrapa.br

Recebido para publicação: $06 / 2001$

Aceito para publicação: 06/2002
} 


\section{INTRODUÇÃO}

A bracatinga (Mimosa scabrella Benth.) é uma espécie florestal pioneira, heliófita em todas as fases de seu desenvolvimento, de rápido crescimento e de ciclo curto. É característica e exclusiva das regiões da Floresta Ombrófila Mista (matas de pinhais), principalmente de associações secundárias, aonde freqüentemente chega a formar povoamentos puros. Com o passar dos anos, no processo sucessional, vai dando lugar à diversas outras espécies, e aos 30 anos de idade aproximadamente, desaparecem por completo (Lorenzi, 1992).

A cultura da bracatinga é realizada, predominantemente em propriedades agrícolas de até 50 hectares. A implantação tradicional, notadamente na Região Metropolitana de Curitiba, é feita por regeneração natural via sementes induzida pela queima dos restos da exploração florestal anterior. No primeiro ano a bracatinga é consorciada com culturas de ciclo curto, principalmente milho e feijão. Após a colheita das culturas agrícolas, não são realizados tratos culturais no povoamento florestal, não havendo portanto, custos de implantação ou manutenção do bracatingal (EMBRAPA, 1998).

O principal e mais importante uso da madeira de bracatinga é para energia, como lenha, e secundariamente como carvão. Essa espécie tem ainda vários outros usos, tais como: planta apícola e forrageira, na recuperação de áreas degradadas, na construção civil como madeira para escoras, na olericultura para construção de estaleiros, em diversas construções nas próprias propriedades rurais e vários outros usos (Carpanezzi, 1989; Rochadelli, 1997).

Então, por todos esses possíveis usos, por formar povoamentos quase puros e devido ao seu rápido crescimento, a bracatinga tem sido uma das espécies florestais mais importantes, especialmente na Região Metropolitana de Curitiba, onde cobre aproximadamente 50 mil hectares.

Apesar do raleamento da bracatinga durante as capinas das culturas anuais no primeiro ano, ainda resta um elevado número de plantas, podendo atingir de 10 a $40 \mathrm{mil}$ árvores por hectare. Embora a mortalidade natural da bracatinga seja intensa, aos 6 a 8 anos de idade (época da rotação), ainda remanescem em torno de 3 mil plantas por hectare. Esta alta densidade certamente prejudica o desenvolvimento das árvores individuais.

A densidade inicial de um povoamento florestal é um dos itens mais importantes de um regime de manejo. Um dos principais objetivos do manejo é dirigir a produção do povoamento de tal maneira que seja aproveitado ao máximo a capacidade produtiva do sítio. No entanto, o efeito da densidade inicial, pode ser diferente sobre as diversas variáveis dendrométricas, tais como diâmetro, altura, forma e consequentemente volume individual médio e área transversal média. Como consequiência tanto o volume por hectare como a área basal por hectare serão afetados pela densidade.

É sabido que além da densidade, o sítio também exerce marcante efeito sobre o crescimento e produção das diversas variáveis dendrométricas, notadamente sobre a altura dominante. Por outro lado, sabe-se também que dados de remedições de mesmas unidades amostrais executadas desde o início da vida até a idade de rotação, constituem a melhor fonte para estudos de crescimento e produção, bem como acompanhar a dinâmica. Tonon (1998), baseando nesses dados de parcelas permanentes instaladas em bracatingais nativos submetidos à diversos tratamentos de densidades iniciais e em 3 diferentes classes de sítio fez um estudo detalhado sobre o comportamento biométrico da bracatinga.

Para efeitos de divulgação de resultados e com base nos estudos de Tonon (1998) este artigo tem como objetivo mostrar os efeitos da densidade inicial e do sítio sobre a dinâmica do crescimento e produção em área basal e volume por hectare.

\section{MATERIAL E MÉTODOS}

\section{Localização e caracterização da área}

Os dados provêm de parcelas permanentes estabelecidas nos municípios de Colombo e Bocaiúva do Sul, PR. Segundo IAPAR (1994), os municípios onde se encontram as parcelas permanentes, têm precipitação média anual de $1400 \mathrm{~mm} \mathrm{e}$ 
umidade relativa do ar de $80 \%$. A precipitação máxima acontece no mês de janeiro $(200 \mathrm{~mm})$ e as mínimas (75-100 mm/mês) ocorrem entre abril e agosto. A temperatura média anual é de $17 \mathrm{oC}$, com média das mínimas de $12 \mathrm{oC}$ e das máximas de $23 \mathrm{oC}$. Acontecem entre 10 e 25 geadas por ano.

Segundo o sistema de classificação de Köppen, o tipo climático é Cfb, que corresponde ao clima temperado propriamente dito. A temperatura média do mês mais frio é inferior a $18 \mathrm{oC}$, com verões frescos, a temperatura média do mês mais quente fica abaixo de 22oC e não há estação seca definida.

Os solos da região, via de regra, são Cambissolos, com diferentes graus de profundidade e fertilidade (Baggio e Carpanezzi, 1997). A altitude é de aproximadamente $950 \mathrm{~m}$ acima do nível do mar.

\section{Implantação do experimento de densidade inicial \\ O experimento foi implantado e} medido pela EMBRAPA-CNPF. O primeiro passo para o seu estabelecimento, segundo relatórios dessa instituição, foi o contato com proprietários de áreas de bracatingais e a procura de áreas com 12 meses de idade. Foram escolhidas 4 propriedades, cujos dados de identificação e localização estão apresentados na Tabela 1.

Tabela 1: Blocos do experimento de densidade (localização e identificação)

\begin{tabular}{llccc}
\hline Proprietário & Localização & Bloco & $\begin{array}{c}\text { Classe de } \\
\text { Sítio }\end{array}$ & $\begin{array}{c}\text { Índice de } \\
\text { Sítio }(\mathrm{m})\end{array}$ \\
\hline Antônio Trevisan & Bocaiúva do Sul & AT & I & 16,8 \\
Benjamin Scremin & Bocaiúva do Sul & BS & II & 13,5 \\
Felício Costa Curta & Bocaiúva do Sul & CC & II & 13,5 \\
Daniel Rosenente & Colombo & ADR & III & 10,2 \\
Daniel Rosenente & Colombo & BDR & III & 10,2 \\
\hline
\end{tabular}

O trabalho de implantação das parcelas foi realizado entre agosto de 1984 e janeiro de 1985. Utilizou-se delineamento em blocos ao acaso. Na propriedade de Daniel Rosenente foram instalados 2 blocos e nas demais $1 \mathrm{em}$ cada, totalizando 5 blocos. Os blocos, daqui por diante, serão identificados pelas siglas constantes na Tabela 1.

Cada bloco constituiu-se de quatro parcelas de $325 \mathrm{~m} 2$ (13 x 25m). Ao redor de cada parcela, foram deixadas bordaduras de
$5 \mathrm{~m}$, resultando numa área total de $805 \mathrm{~m} 2$. Fezse então um desbaste nas parcelas e bordaduras, deixando apenas o número de árvores correspondente à densidade desejada. $\mathrm{O}$ desbaste foi feito à foice e, paralelamente, foi efetuada uma roçada, eliminando matocompetição. Nas parcelas testemunha não foi realizado desbaste. Os tratamentos são mostrados na Tabela 2

Tabela 2: Tratamentos do experimento de densidade inicial.

\begin{tabular}{ccc}
\hline Tratamento & № Plantas/ha & № plantas/parcela \\
\hline 1 & 2000 & 65 \\
2 & 4000 & 130 \\
3 & 8000 & 260 \\
4 & Testemunha & Total \\
\hline
\end{tabular}

De modo geral, foram retiradas as árvores menores, com base nos dados obtidos no levantamento preliminar das sub-parcelas. Após o desbaste, realizou-se nova medição de altura de todas as árvores remanescentes. Esses dados correspondem à medição 1 .

\section{Coleta de dados das parcelas permanentes}

Nas duas primeiras medições das parcelas permanentes foram determinados altura (h) e número de árvores/ha $(\mathrm{N})$ e nas seguintes mediu-se h, $\mathrm{N}$ e DAP (diâmetro à altura do peito). Foram usadas varas telescópicas para a medição das alturas e sutas para os DAPs. 
Os meses foram transformados em decimais, porque muitas vezes as remedições dos blocos não foram realizadas na mesma época. Dessa forma foi possível isolar diferenças devidas à idade e não ao tratamento e/ou sítio. Não houve medição na idade de 3 anos. Em média, utilizaram-se as idades 1; 2,2; 4,$1 ; 5,1 ; 6,3$ e 7,6 na confecção de gráficos. Nas 2 primeiras ocasiões mediu-se apenas a altura e número de árvores. A partir daí, mediu-se também os DAP.

\section{Base de dados}

Cada parcela permanente teve seus dados de campo organizados em um arquivo. As variáveis $\mathrm{N}$, DAP e $\mathrm{h}$ foram medidas diretamente no campo e suas médias computadas por parcela. A altura dominante foi determinada pela média de altura das 3 árvores de maiores DAPs na parcela de $325 \mathrm{~m} 2$, o que significa que se utilizou o método das 100 maiores árvores/ha. O volume individual (v) foi estimado utilizando-se a equação desenvolvida por Ahrens (1981): $\mathrm{v}=$ 0,3879.DAP2.h (DAP e altura em metros). A área basal $(\mathrm{G})$ e o volume por hectare $(\mathrm{V})$ foram obtidos por somatório das áreas transversais e volumes individuais e posterior extrapolação do valor da parcela para um hectare.

Para as parcelas permanentes, calculou-se ainda a mortalidade percentual, segundo a fórmula: $\mathrm{M} \%=[(\mathrm{N} 1-\mathrm{N} 2) / \mathrm{N} 1] 100$, onde $\mathrm{N} 1$ é o número de árvores na medição anterior e N2 é o número de árvores na medição atual. Para completar a base de dados, fez-se a distribuição das parcelas nas classes de sítio, de acordo com a classificação desenvolvida por Machado et al. (1997) reorganizada por Tonon (1998).

\section{Análise dos efeitos da densidade e do sítio na produção}

Para essa análise, foram utilizados os dados das parcelas permanentes do experimento de densidades anteriormente descrito. Avaliaram-se os efeitos da densidade (número de árvores/ha) inicial e do sítio sobre: volume por hectare $(\mathrm{V})$ e área basal por hectare $(\mathrm{G})$. A análise dos efeitos sobre DAP médio, altura média (h), altura dominante (Hdom), área transversal individual (g) média, volume individual médio (v) e mortalidade foi contemplada em outro artigo.

\section{Análise gráfica}

Fez-se uma observação visual preliminar da influência da densidade e do sítio sobre as diversas variáveis do povoamento, através de gráficos. Plotou-se a evolução no tempo de cada variável como função dos tratamentos e então como função dos blocos. Esses gráficos deram uma boa idéia da tendência das variáveis. Para a confecção dos gráficos para os tratamentos, no entanto, fez-se necessário que se estimasse as variáveis que estavam faltando nas últimas medições.

\section{Estimativas dos blocos ausentes nas últimas medições}

Por motivos alheios à vontade dos pesquisadores envolvidos, não se tem informação do bloco AT na $5^{\text {a }}$ medição nem dos blocos AT e BS na $6^{\underline{a}}$. Para se compreender o comportamento dos tratamentos no tempo, no entanto, essa ausência seria um problema. Como os blocos faltantes são justamente o único da classe de sítio I e um dos 2 da classe II, muitas vezes terse-ia a impressão que os valores das variáveis diminuem nessas duas épocas.

Resolveu-se, então, estimar os valores desses blocos somente para facilitar a análise gráfica do efeito médio dos tratamentos (ou seja, esses dados estimados só foram usados no item .1 de cada grupo de variáveis). Todas as estimativas se iniciaram a partir da equação de classificação de sítio desenvolvida por Machado et al. (1996), que, rearranjada para estimar altura dominante a uma determinada idade a partir de Hdom a uma outra idade, ficou assim:

$$
\operatorname{Hdom}_{2}=\operatorname{Hdom}_{1} \cdot\left[\frac{I-\exp \left(-0,08325 \cdot I_{2}\right)}{I-\exp \left(-0,08325 \cdot I_{1}\right)}\right]^{0,58798}
$$

onde: $\quad \operatorname{Hdom}_{2}=$ altura dominante na idade $2(\mathrm{~m})$ $\operatorname{Hdom}_{1}=$ altura dominante na idade $1(\mathrm{~m})$ $\mathrm{I}_{2}=$ idade em que se quer estimar Hdom (anos)

$\mathrm{I}_{1}=$ idade de Hdom conhecida (anos).

A partir das alturas dominantes foram estimadas as demais variáveis. A altura média, que apresentou um coeficiente de correlação 
de 0,92 com a altura dominante, foi estimada como função dessa variável. A estimativa do DAP a princípio foi tentada por meio de relação hipsométrica, mas essa se revelou muito fraca. Acrescentou-se então a variável idade, que melhorou os resultados. No entanto, algumas vezes o DAP estimado, só com base na altura e idade, era igual ou menor que o DAP médio da mesma parcela na medição anterior. Por isso, adicionaram-se ainda as variáveis DAP médio da parcela na medição anterior e densidade inicial.

Os valores estimados de DAP permitiram a estimativa de diâmetro médio quadrático $(\mathrm{dg})$ e, a partir desse, da área transversal. Tanto dg como g apresentaram um coeficiente de correlação de 0,99 com o DAP. Com relação ao volume, utilizou-se a equação de Ahrens (1981) para cada árvore individual. Nesse caso, no entanto, o que se queria estimar era o volume médio de cada parcela a partir de dados médios de DAP e $\mathrm{h}$.

As variáveis do povoamento $(\mathrm{G} \mathrm{e} \mathrm{V})$ foram estimadas com base em área transversal individual (g) e volume individual (v) e no número de árvores/ha. Assim, diversos modelos foram testados para a estimativa de $\mathrm{N}$, para cada tratamento e para os sítios I e II, uma vez que não faltavam dados para o sítio III.

\section{Análise de variância}

A seguir, fez-se a avaliação estatística desses efeitos através de análise de variância, que desdobra a variância em fontes de variação identificáveis. A análise de variância foi efetuada utilizando-se o valor médio por tratamento e bloco, separadamente por variável e idade de medição. Foi usado um nível de significância de 5\% para "F".

\section{Comparação entre classes de sítio}

Quando a fonte de variação é de natureza qualitativa, como no caso das classes de sítio, a comparação entre os fatores deve ser feita através de um teste de comparação múltipla de médias. O teste de Tukey ao nível de $5 \%$ foi utilizado para detectar diferenças significativas entre eles.

A realização desse teste, no entanto, requereu o uso de um artifício. Muitas vezes, as medições não foram realizadas exatamente na mesma idade. Ou seja, na mesma medição 4 , por exemplo, um bloco foi medido aos 4,8 , outros dois aos 5,0 e os dois restantes aos 5,4 anos de idade. Assim, a diferença nas médias das variáveis poderiam ser também devidas a essa desigualdade.

Para se fazer a comparação entre os blocos, essa diferença devida à idade precisou ser eliminada. Para isso, usou-se interpolação para se obter todas as medições à mesma idade. Portanto, só para a realização desse teste, assumiu-se que, se para um determinado tratamento e sítio, o DAP medido era de 8,1 $\mathrm{cm}$ aos 4,2 anos de idade e de $8,8 \mathrm{~cm}$ na idade de 5,4, na idade de 5 anos o DAP esperado seria de $8,6 \mathrm{~cm}$. Apesar de se saber que o padrão de evolução dessas variáveis no tempo não é linear, usou-se esse tipo de interpolação por tratar-se de intervalos de idade muito pequenos. Assim esses dados, interpolados ou observados, mas sempre à mesma idade, foram utilizados no teste de Tukey.

\section{RESULTADOS E DISCUSSÃO}

\section{Crescimento em função da densidade inicial}

A área basal e o volume/ha são variáveis que dependem do $\mathrm{N}$ e do DAP médio, e o V é influenciado ainda pela altura média e pela forma da árvore.

Uma vez que as equações para g e v já haviam sido determinadas, faltavam os valores de $\mathrm{N}$ para a estimativa dos valores das últimas medições. A Tabela 3 apresenta os modelos escolhidos para cada combinação de tratamento e sítio e a Tabela 4 mostra seus coeficientes e estatísticas. Os produtos dados pelas estimativas de $\mathrm{N}$ e de $\mathrm{g}$ ou $\mathrm{v}$ originaram os valores de $\mathrm{G}$ e $\mathrm{V}$ nos casos em que não existiam esses valores. 
Tabela 3: Modelos utilizados para estimar o numero de arvores por hectare $(\mathrm{N})$.

\begin{tabular}{ccl}
\hline Trat. & Sítio & \multicolumn{1}{c}{ Modelo } \\
\hline 1 & I & $\mathrm{N}_{2}=\mathrm{a}+\mathrm{b} \cdot \mathrm{I}_{1}$ \\
1 & II & $\mathrm{N}_{2}=\mathrm{N}_{1} \cdot \exp \left[\mathrm{a} \cdot\left(\mathrm{b}^{\mathrm{I} 2}-\mathrm{b}^{\mathrm{I1}}\right)\right]$ \\
2 & I & $\mathrm{N}_{2}=\mathrm{a}+\mathrm{b} \cdot \mathrm{I}_{2}$ \\
2 & II & $\mathrm{N}_{2}=\mathrm{a}+\mathrm{b} \cdot \mathrm{I}_{1}$ \\
3 & I & $\mathrm{N}_{2}=\mathrm{N}_{1}-\mathrm{N}_{1} \cdot\left\{\left[1-\exp \left(-\mathrm{a} \cdot\left(\mathrm{I}_{2}-\mathrm{I}_{1}\right)\right)\right]^{\mathrm{b}}\right\}$ \\
3 & II & $\mathrm{N}_{2}=\left[\mathrm{N}_{1}^{\mathrm{a}}+\mathrm{b} \cdot\left(\mathrm{I}_{2}-\mathrm{I}_{1}\right)^{\mathrm{c}}\right]^{(1 / \mathrm{a})}$ \\
4 & I & $\mathrm{N}_{2}=\mathrm{a}+\mathrm{b} \cdot \mathrm{N}_{1}$ \\
4 & II & $\mathrm{N}_{2}=\mathrm{a}+\mathrm{b} \cdot \mathrm{N}_{1}$ \\
\hline
\end{tabular}

Onde: $\quad \mathrm{N}_{2}=$ número de árvores/ha atual, na idade 2

$\mathrm{N}_{1}=$ número de árvores/ha na medição anterior (idade 1)

$\mathrm{I}_{2}=$ idade atual (anos)

$\mathrm{I}_{1}=$ idade da medição anterior (anos)

As Figuras 1 e 2 mostram a evolução das variáveis $\mathrm{G}$ e $\mathrm{V}$ em função da densidade inicial. Devido às influências exercidas por diversas outras variáveis, seu comportamento não apresenta tendências tão claras quanto o dos demais parâmetros já analisados. Percebese, para o V, uma superioridade do tratamento
4 mil plantas/ha já a partir da segunda medição dessa variável (medição 4 - aproximadamente 5 anos de idade). Já para a variável $\mathrm{G}$, esse mesmo tratamento também supera os demais com o passar do tempo, apresentando o maior valor na última medição (aproximadamente 7,6 anos de idade).

Tabela 4: Coeficientes e estatísticas das equações para estimativa de valores de N, por densidade e sítio

\begin{tabular}{ccccccc}
\hline Trat. & Sítio & $\mathrm{a}$ & $\mathrm{b}$ & $\mathrm{C}$ & $\mathrm{R}^{2}$ & $\mathrm{~S}_{\mathrm{yx}} \%$ \\
\hline 1 & I & 1729,33 & $-127,54$ & & 0,71 & 7,07 \\
1 & II & 0,000134 & 3,05842 & & 0,82 & 7,88 \\
2 & I & 3653,046 & $-316,84$ & & 0,99 & 0,67 \\
2 & II & 4112,80 & $-391,60$ & & 0,90 & 8,76 \\
3 & I & $-0,5783$ & 1,7810 & & 0,99 & 6,10 \\
3 & II & 0,4319 & $-2,5039$ & 2,1800 & 0,97 & 11,24 \\
4 & I & 842,63 & 0,3330 & & 0,99 & 4,27 \\
4 & II & 567,47 & 0,5313 & & 0,98 & 9,39 \\
\hline
\end{tabular}



Figura 1: Área basal em função da densidade inicial em cada uma das idades. 


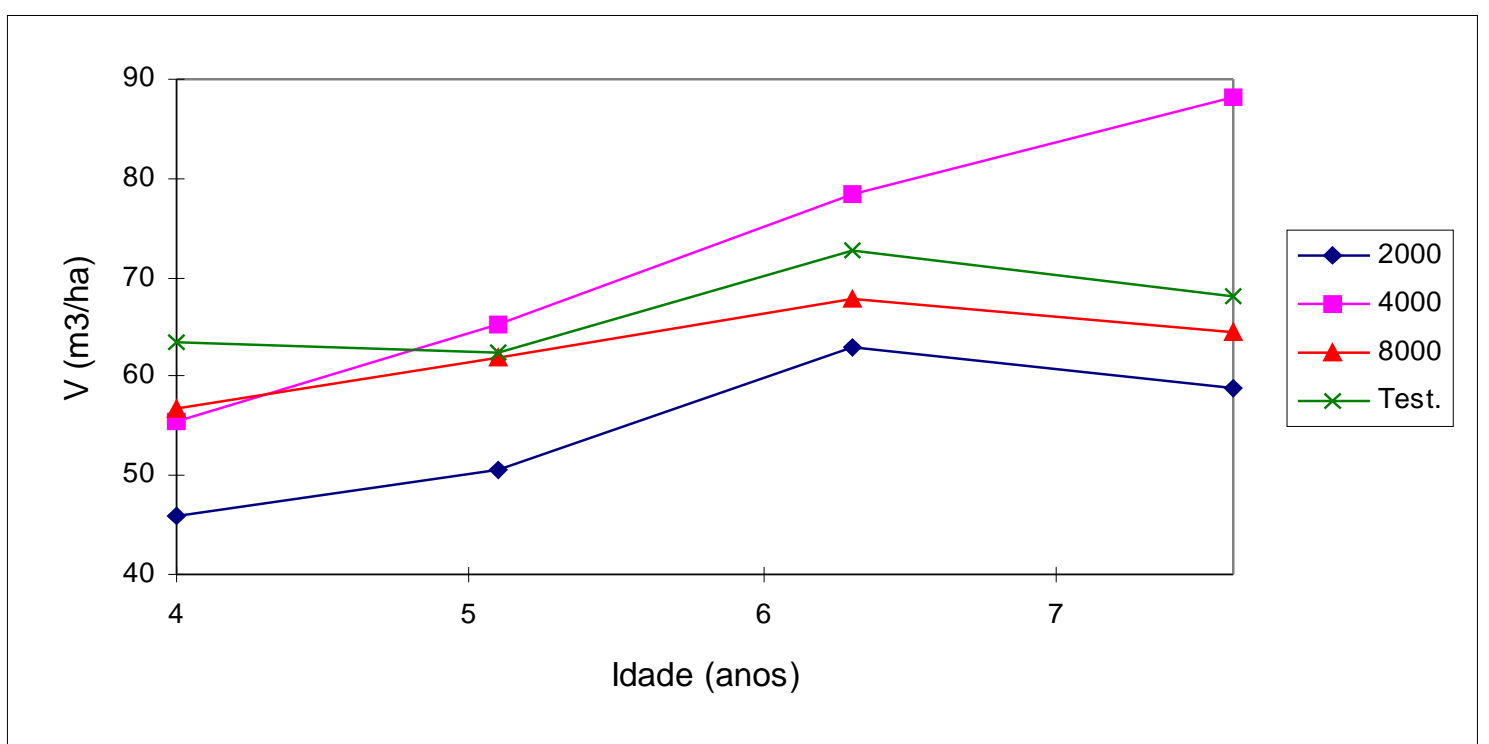

Figura 2: Volume/ha em função da densidade inicial em cada uma das idades.

Para se compreender esses resultados, necessita-se analisar a evolução de todas as variáveis que os influenciaram: DAP (ou ainda g ou dg), altura média e mortalidade em função dos tratamentos.

De acordo com Tonon (1998) ao analisar os gráficos de evolução da mortalidade e do DAP médio, pode-se entender a evolução da área basal. Aos 4 anos de idade, $\mathrm{G}$ é menor para menores números de árvores/ha, o que é compreensível, e principalmente considerando-se que $\mathrm{N}$ varia muito: entre 7489 (testemunha) e 1674 (tratamento 1). Assim, apesar dos tratamentos com densidades maiores terem DAPs médios menores, o grande número de árvores compensa essa diferença.

No ano seguinte, a ordem dos tratamentos em magnitude da $G$ continua a mesma, mas a tendência durante o intervalo entre as medições muda: o valor da testemunha cai consideravelmente, os tratamentos $8 \mathrm{mil} \mathrm{e}$ 2 mil permanecem mais ou menos estáveis, enquanto que o tratamento 4 mil aumenta. Os tratamentos 2, 3 e 4 (respectivamente, 4 mil, 8 mil plantas/ha e testemunha) convergem, apresentando valores de $\mathrm{G}$ muito próximos na idade aproximada de 5 anos.

Tonon (1998) verificou que durante o período entre as medições 3 e 4 , o $\mathrm{N}$ da testemunha caiu em $13 \%$. Essa taxa também foi de $13 \%$ para o tratamento $3,12 \%$ para o $2 \mathrm{e}$ de $8 \%$ para o tratamento 1 . Os DAPs médios de todos os tratamentos aumentaram no período analisado. Com base nessas informações, pode-se concluir que o $\mathrm{G}$ da testemunha caiu devido à alta mortalidade e que o dos tratamentos 1 e $3(2$ mil e 8 mil plantas/ha) se manteve constante porque a mortalidade foi compensada pelo crescimento das árvores remanescentes.

Quanto ao tratamento 2 (4 mil plantas/ha), quando comparado aos tratamentos 3 e 4 pode-se compreender o crescimento em função do maior DAP. Quando comparado ao tratamento 1, embora sua mortalidade tenha sido mais alta, o crescimento do DAP foi mais acentuado do que para o $1(0,8 \mathrm{~cm}$ de incremento periódico anual (IPA) daquele contra 0,5 desse último). Esse crescimento, aliado ao maior número absoluto de árvores/ha, explica o aumento da área basal média dessa densidade. Convém salientar que quando se fala em DAP, está se falando de médias. Por isso, crescimento não significa necessariamente crescimento físico, mas pode ser também um aumento da média por mortalidade de árvores menores. $\mathrm{O}$ mais provável é que se trate de uma combinação das duas causas.

O período seguinte caracterizou-se por uma baixa mortalidade em todos os tratamentos. Dessa forma, o G aumentou em todos eles, principalmente no 1 , que, embora tenha tido o incremento corrente mais baixo em termos de DAP médio entre todos os 
tratamentos, também teve mortalidade muito baixa (63 árvores apenas, contra 491 árvores, que representam os $2 \%$ de mortalidade da testemunha). $\mathrm{Na}$ época da medição (aproximadamente 6,3 anos de idade), o tratamento 2 (4 mil plantas/ha) ultrapassa o tratamento 3 (8 mil), sendo superado apenas pela testemunha.

Já o último período de medição voltou a apresentar taxas de mortalidade mais elevadas. Isso causou a queda do valor de $\mathrm{G}$ para os tratamentos 1,3 e testemunha. O tratamento 2 (4 mil plantas/ha), que apresentou o maior incremento de DAP médio (IPA de $1,05 \mathrm{~cm} / \mathrm{ano}$ ) e cuja mortalidade absoluta foi de apenas 467 árvores, resultou no único tratamento cuja área basal aumentou no espaço de tempo analisado, ultrapassando todos os demais. O tratamento 1, embora tenha perdido somente 415 árvores, teve um incremento baixo $(0,9 \mathrm{~cm} / \mathrm{ano})$, enquanto que o tratamento 4 teve um IPA quase tão grande quanto o do tratamento 2, mas teve uma mortalidade absoluta de 1392 árvores. O tratamento 3 teve incremento e mortalidades intermediárias, quando comparados aos demais tratamentos.

Para a variável volume/ha (V), a análise feita para a área basal/ha $(\mathrm{G})$ pode ser aproveitada. $\mathrm{O}$ comportamento de $\mathrm{V}$ foi praticamente o mesmo de $\mathrm{G}$, com a diferença que o tratamento 2 ultrapassou os demais logo aos 5 anos. Isso é perfeitamente compreensível, porque o $\mathrm{V}$ sofre também a influência da altura média, além da do DAP e N. Conforme observado por Tonon (1998), a altura média do tratamento 2 (4 mil plantas) excedeu as demais justamente nessa idade.

Em resumo, aos 7,6 anos de idade a produção volumétrica é diretamente proporcional à densidade inicial (testemunha > 8 mil plantas/ha > 2 mil plantas/ha), com exceção do tratamento 2 (4 mil plantas/ha), que teve crescimento consideravelmente maior.

Baggio et al. (1992) também encontraram essa relação de proporcionalidade direta, enquanto que Laurent et al. (1990) encontraram volumes maiores para povoamentos raleados aos 14 e 24 meses de idade do que para testemunhas.

Quanto ao incremento, o incremento médio anual (IMA) de ambas as variáveis teve seu valor máximo aos 4,1 anos de idade (ou antes), e a partir daí o valor passou a cair. Com relação aos tratamentos, o IMA comportou-se de forma oposta às demais variáveis: o valor foi diretamente proporcional à densidade inicial. A exceção foi o tratamento 2 , cujo IMA foi maior do que o de todos os demais. $\mathrm{O}$ IPA não mostrou nenhuma tendência, mas o do tratamento 2 também foi sempre superior.

\section{Crescimento em função do sítio}

Os blocos (sítios) parecem exercer pouca influência sobre a área basal, mas demonstram algum efeito sobre o volume. Essa diferença é devida ao fato que o volume/ha é dependente também da altura, que é fortemente afetada pelo sítio. As variáveis $\mathrm{G}$ e $\mathrm{V}$ como função dos blocos estão representadas nas figuras 3 e 4 .



Figura 3: Área basal em função dos blocos nas diversas idades de medição. 


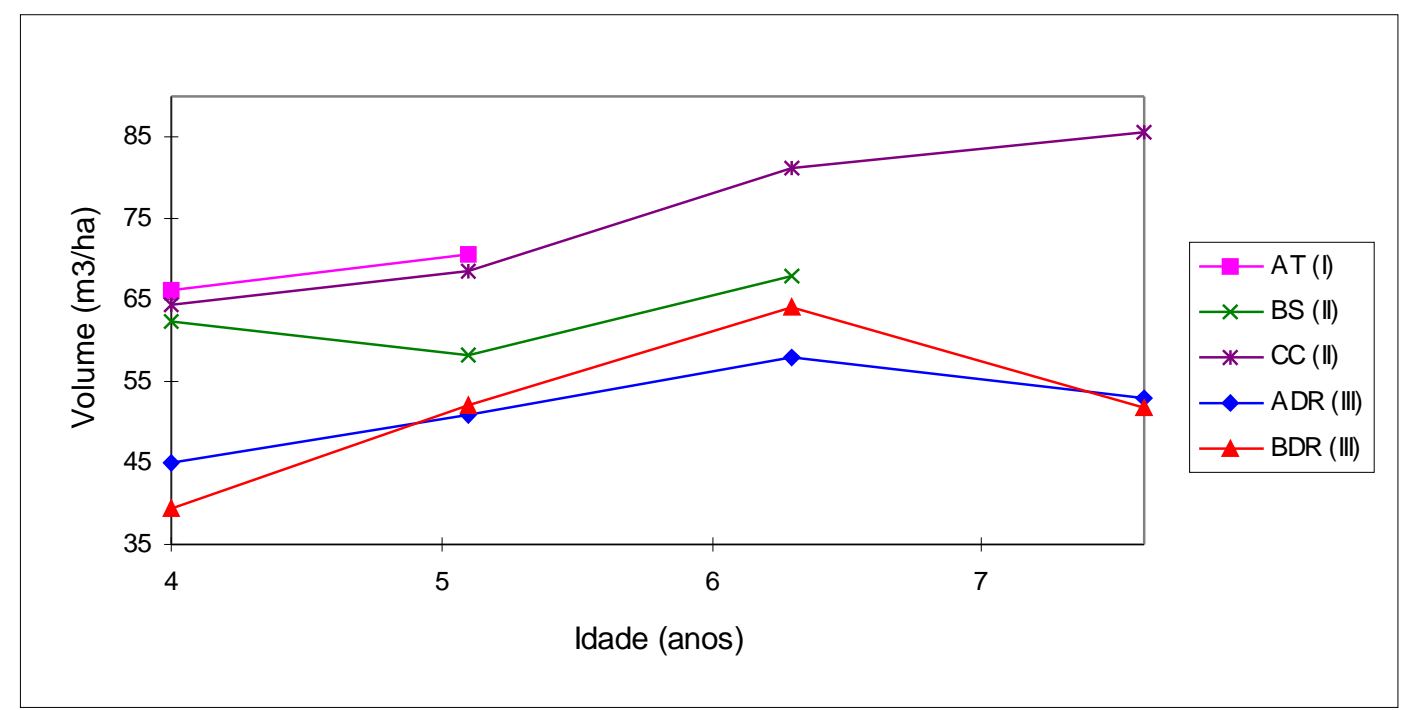

Figura 4: Volume/ha em função dos blocos nas diversas idades de medição.

Mais uma vez, para compreender o padrão demonstrado nas figuras 3 e 4 , é necessária uma análise das variáveis das quais G e V são funções: área transversal ou volume individual, respectivamente, e N. As duas primeiras (g e v) têm suas evoluções no tempo em função dos blocos conforme estudo de Tonon (1998). A mesma autora também estudou a evolução do número de árvores/ha, em função dos blocos.

Para a área basal, analisando-se o gráfico de área transversal média, Tonon (1998) percebeu-se que, à idade de 4 anos, a diferença entre os valores dos 3 primeiros blocos é pequena: 0,0045 para $\mathrm{AT}, 0,0041$ para $\mathrm{BS}$ e 0,0039 para CC. Assim, o maior número de árvores do bloco $\mathrm{CC}$, seguido de BS e AT, explica a ordem de $\mathrm{G}$, nessa idade, para esses blocos. Para os blocos ADR e BDR os valores de g são de 0,0032 e 0,0027, respectivamente. O N consideravelmente mais alto de BDR permite que seus valores de $G$ sejam quase iguais, embora ainda menores que os dos blocos das classes I e II.

Durante o período seguinte, a alta mortalidade do bloco AT não compensou seu crescimento, e sua área basal média caiu. Os valores de $\mathrm{G}$ para os blocos CC e BS também diminuíram, embora essa queda seja mais suave para CC, cujo $\mathrm{g}$ médio aumentou numa proporção maior que o de $\mathrm{BS}$ e cujo $\mathrm{N}$ ainda era consideravelmente maior, apesar da taxa de mortalidade mais alta. A área basal do bloco ADR continuou mais ou menos constante, com o crescimento compensando a mortalidade e a do bloco BDR aumentou, devido ao grande número de árvores e à mais alta taxa de crescimento entre todos os blocos (30\%, passando de 0,002747 para 0,003575). Esse último bloco ultrapassou AT e BS nessa medição.

O período seguinte se caracteriza pelas baixas taxas de mortalidade de maneira geral, causando um aumento na área basal de todos os blocos. Já no último período de medição, a mortalidade volta a aumentar, gerando uma diminuição nos valores de $\mathrm{G}$, atenuada no bloco CC pelo crescimento de $39 \%$ na área transversal média (IPA de $0,001814 \mathrm{~m}^{2} / \mathrm{ha} / \mathrm{ano}$ ).

A variável volume/ha foi afetada pela mortalidade da mesma maneira. A diferença é causada pela evolução do volume individual. Primeiramente, em volume médio o bloco AT foi muito superior aos demais. Assim, mesmo tendo um número de árvores bem menor, o $\mathrm{V}$ desse bloco é maior que o dos outros. Além disso, a distância entre os blocos das diferentes classes de sítio foi maior para $\mathrm{v}$ do que para $\mathrm{g}$. Por isso, o volume/ha do bloco BDR, apesar dos altos valores de $\mathrm{N}$, não superou o do bloco BS. A última diferença entre as duas variáveis foi que a queda nos valores de $\mathrm{V}$ no último período não é tão acentuada quanto a dos valores de $\mathrm{G}$ (inclusive para o bloco $\mathrm{CC}$ ocorreu um leve aumento).

\section{Análise de variância para efeitos de densidade e sítio}

Os resultados da análise de variância para as variáveis área basal e volume/ha encontram-se nas Tabelas 5 e 6. 
Tabela 5: Análises de variância para área basal nas diversas medições.

\begin{tabular}{|l|c|r|r|r|c|}
\hline \multicolumn{7}{|c|}{ FV } & GL & SQ & QM & \multicolumn{1}{c|}{ F } & Probabilidade \\
\hline Densidade & 3 & 57,22641 & 19,07547 & 10,33498 & $0,0012^{* *}$ \\
Sítio & 4 & 20,79211 & 5,19803 & 2,81626 & 0,0735 \\
Erro & 12 & 22,14863 & 1,84572 & & \\
\hline TOTAL & 19 & 100,16715 & & & \\
\hline
\end{tabular}

\begin{tabular}{|c|c|c|c|c|c|}
\hline \multicolumn{6}{|c|}{ MEDIÇÃO 4} \\
\hline FV & GL & SQ & QM & $\mathrm{F}$ & Probabilidade \\
\hline Densidade & 3 & 25,63902 & 8,54634 & 6,42860 & $0,0076^{* *}$ \\
\hline Sítio & 4 & 10,90050 & 2,72512 & 2,04985 & 0,1510 \\
\hline Erro & 12 & 15,95310 & 1,32942 & & \\
\hline TOTAL & 19 & 52,49261 & & & \\
\hline \multicolumn{6}{|c|}{ MEDIÇÃO 5} \\
\hline FV & GL & SQ & QM & $\mathrm{F}$ & Probabilidade \\
\hline Densidade & 3 & 19,89855 & 6,63285 & 4,38470 & $0,0367 *$ \\
\hline Sítio & 3 & 17,23688 & 5,74563 & 3,79820 & 0,0520 \\
\hline Erro & 9 & 13,61452 & 1,51272 & & \\
\hline TOTAL & 15 & 50,74995 & & & \\
\hline \multicolumn{6}{|c|}{ MEDIÇÃO 6} \\
\hline $\mathrm{FV}$ & GL & SQ & QM & $\mathrm{F}$ & Probabilidade \\
\hline Densidade & 3 & 36,18405 & 12,06135 & 2,05227 & 0,2081 \\
\hline Sítio & 2 & 30,83201 & 15,41601 & 2,62307 & 0,1519 \\
\hline Erro & 6 & 35,26248 & 5,87708 & & \\
\hline TOTAL & 11 & 102,27854 & & & \\
\hline
\end{tabular}

Tabela 6: Análises de variância para volume/ha nas diversas medições.

\begin{tabular}{|c|c|c|c|c|c|}
\hline \multicolumn{6}{|c|}{ MEDIÇÃO 3} \\
\hline FV & GL & SQ & QM & $\mathrm{F}$ & Probabilidade \\
\hline Densidade & 3 & 781,44516 & 260,48172 & 6,68670 & $0,0066^{* *}$ \\
\hline Sítio & 4 & 2452,59106 & 613,14777 & 15,73982 & $0,0001 * *$ \\
\hline Erro & 12 & 467,46249 & 38,95521 & & \\
\hline TOTAL & 19 & 3701,49872 & & & \\
\hline \multicolumn{6}{|c|}{ MEDIÇÃO 4} \\
\hline $\mathrm{FV}$ & GL & SQ & $\mathrm{QM}$ & $\mathrm{F}$ & Probabilidade \\
\hline Densidade & 3 & 629,48415 & 209,82805 & 4,11363 & $0,0320^{*}$ \\
\hline Sítio & 4 & 1335,59009 & 333,89752 & 6,54598 & $0,0049 * *$ \\
\hline Erro & 12 & 612,09631 & 51,00803 & & \\
\hline TOTAL & 19 & 2577,17055 & & & \\
\hline \multicolumn{6}{|c|}{ MEDIÇÃO 5} \\
\hline FV & GL & SQ & QM & $\mathrm{F}$ & Probabilidade \\
\hline Densidade & 3 & 509,49902 & 169,83301 & 2,64423 & 0,1129 \\
\hline Sítio & 3 & 1169,96750 & 389,98917 & 6,07198 & $0,0152 *$ \\
\hline Erro & 9 & 578,04916 & 64,22768 & & \\
\hline TOTAL & 15 & 2257,51568 & & & \\
\hline \multicolumn{6}{|c|}{ MEDIÇÃO 6} \\
\hline FV & GL & SQ & QM & $\mathrm{F}$ & Probabilidade \\
\hline Densidade & 3 & 1863,29297 & 621,09766 & 1,97266 & 0,2196 \\
\hline Sítio & 2 & 2937,80518 & 1468,90259 & 4,66535 & 0,0599 \\
\hline Erro & 6 & 1889,12109 & 314,85352 & & \\
\hline TOTAL & 11 & 6690,21924 & & & \\
\hline
\end{tabular}


Convém ter em mente a forma de cálculo utilizada para volume: uma mesma equação para todos os tratamentos e sítios. $\mathrm{Na}$ prática sabe-se que a densidade do povoamento e o sítio influenciam a forma da árvore. Assim, as densidades mais baixas e os sítios mais pobres tendem a apresentar árvores mais cônicas. Portanto, os resultados apresentados aqui, embora dêem uma idéia dos volumes por unidade de área, não são expressivamente acurados. Além disso, apesar do volume do tratamento 2 ser superior aos demais na última medição, a diferença real entre esse e os demais tratamentos pode ser diferente do que a obtida com essa forma de cálculo.

Para ambas as variáveis os tratamentos mostram diferença significativa nas duas primeiras medições (aproximadamente 4 e 5 anos de idade). Já nas duas medições seguintes, as densidades não afetaram significativamente o $\mathrm{G}$ e o V.

A princípio, poderia se concluir que, sendo o objetivo de manejo do povoamento de bracatinga a maximização do volume por unidade de área e a rotação entre 6 e 7,5 anos de idade, a densidade inicial não é relevante. Convém, no entanto, salientar que mesmo para lenha existem diâmetros e comprimentos mínimos requeridos para as toras, que não estão sendo considerados aqui, uma vez que não se dispõe de dados para ajuste de equações de afilamento.

Conforme anteriormente discutido, o volume/ha e a área basal são uma combinação das variáveis volume individual ou área transversal média, respectivamente, e número de árvores por hectare. $\mathrm{O}$ fato de não se observar diferença significativa entre os diferentes tratamentos significa que as duas variáveis independentes citadas estão se compensando.

Assim, o fato de dois povoamentos possuírem o mesmo volume/ha, não significa que a quantidade de madeira comerciável seja a mesma. Para ilustrar esse efeito, a Tabela 7 apresenta o número de árvores por classe de diâmetro nas parcelas, para cada tratamento, na época da última medição (aproximadamente 7,6 anos). Os dados da Tabela são as freqüências absolutas e relativas para cada densidade

Tabela 7: Distribuição de frequiência diamétrica absoluta (F.A.) e relativa (F.R.) para diferentes densidades iniciais, aos 7,6 anos de idade por parcela de $325 \mathrm{~m} 2$ de área.

\begin{tabular}{ccc|cc|cc|cc}
\hline & \multicolumn{7}{c}{ Tratamentos } \\
\cline { 2 - 9 } Classes de & \multicolumn{2}{c|}{2000} & \multicolumn{2}{c}{4000} & \multicolumn{2}{c}{8000} & \multicolumn{2}{c}{ Testemunha } \\
\cline { 2 - 9 } DAP $(\mathrm{cm})$ & F. A. & F. R. & F. A. & F. R. & F. A. & F. R. & F. A. & F. R. \\
\hline$\leq 4$ & 0 & 0,0 & 2 & 1,1 & 4 & 1,7 & 16 & 6,7 \\
$4-8$ & 11 & 10,9 & 47 & 26,9 & 146 & 62,9 & 145 & 60,4 \\
$8-12$ & 72 & 71,3 & 90 & 51,4 & 74 & 31,9 & 68 & 28,3 \\
$12-16$ & 17 & 16,8 & 35 & 20,0 & 7 & 3,0 & 11 & 4,6 \\
$\geq 16$ & 1 & 1,0 & 1 & 0,6 & 1 & 0,4 & 0 & 0,0 \\
\hline Total & 101 & $100 \%$ & 175 & $100 \%$ & 232 & $100 \%$ & 240 & $100 \%$ \\
\hline
\end{tabular}

Os dados da Tabela 7 provam que, apesar das variáveis G e V não apresentarem diferença significativa causada pelos tratamentos, as estruturas dos povoamentos são bem diferentes. À idade aproximada de 7,6 anos, as parcelas submetidas ao tratamento 1 possuem $71 \%$ de suas árvores com DAP entre 8 e $12 \mathrm{~cm}$ e $17 \%$ entre 12 e 16 e as sujeitas ao tratamento 2 têm $51 \%$ e $20 \%$ nas mesmas classes, respectivamente. Os demais tratamentos, no entanto, mostram uma distribuição bem diferente, com a maior parte das árvores na classe de DAP entre 4 e $8 \mathrm{~cm}$.
Os tratamentos 3 e 4 têm, respectivamente, 96,5 e 95,4\% das árvores com diâmetro menor que $12 \mathrm{~cm}$.

Essas considerações devem servir para que o resultado da ANOVA, que não indica diferença entre os tratamentos e os sítios nas idades mais avançadas, seja visto com cautela. Seria precipitado afirmar que diferentes densidades iniciais ou qualidades de sítio não afetam a produção total do bracatingal, sem examinar outros fatores que podem influenciar o uso e a comercialização da madeira. 
Já os blocos geraram diferenças significativas para a variável $\mathrm{V}$ em todas as medições, com exceção da última, que coincide com a ausência de dados de um bloco da classe de sítio I e outro da classe II. Esse efeito já havia sido notado no gráfico de evolução dessa variável em função dos blocos. Para a área basal, somente na medição 5 a diferença foi estatisticamente significativa.

Apesar da ausência da classe de sítio I, elaborou-se uma distribuição de freqüências, como a Tabela 7, para as classes de sítio II e
III, à idade de 7,6 anos. A Tabela 8 mostra esses dados.

Embora a classe III tivesse mais árvores (porque existiam duas parcelas na última medição, contra uma da classe II), mais de $70 \%$ das árvores da classe de sítio II tinham entre 8 e $16 \mathrm{~cm}$, enquanto que mais da metade das pertencentes à classe III tinham entre 4 e 8 $\mathrm{cm}$. Além disso, a classe III não tinha nenhuma árvore com DAP maior que $16 \mathrm{~cm}$, enquanto que elas existiam na classe de sítio II. Se existissem parcelas na classe I, a diferença certamente ficaria ainda mais evidente.

Tabela 8: Distribuição de freqüência diamétrica absoluta (F.A.) e relativa (F.R.) para diferentes classes de sítio, aos 7,6 anos de idade por parcela de $325 \mathrm{~m} 2$ de área.

\begin{tabular}{ccc|cc}
\hline & \multicolumn{4}{c}{ Classes de sítio } \\
\cline { 2 - 5 } Classes de & \multicolumn{3}{c}{ II } & III \\
\cline { 2 - 5 } DAP $(\mathrm{cm})$ & F. A. & F. R. & F. A. & F. R. \\
\hline$\leq 4$ & 3 & 1,4 & 19 & 3,6 \\
$4-8$ & 57 & 26,1 & 292 & 55,0 \\
$8-12$ & 107 & 49,1 & 197 & 37,1 \\
$12-16$ & 47 & 21,6 & 23 & 4,3 \\
$\geq 16$ & 4 & 1,8 & 0 & 0,0 \\
\hline Total & 218 & $100 \%$ & 531 & $100 \%$ \\
\hline
\end{tabular}

\section{Efeito da densidade inicial}

As tendências da área basal e do volume/ha em função da densidade inicial do povoamento está representada nas figuras 5 e
6. Em todos os casos, percebe-se um aumento das variáveis para o tratamento 2 (4mil plantas/ha) em relação ao 1 (2mil).

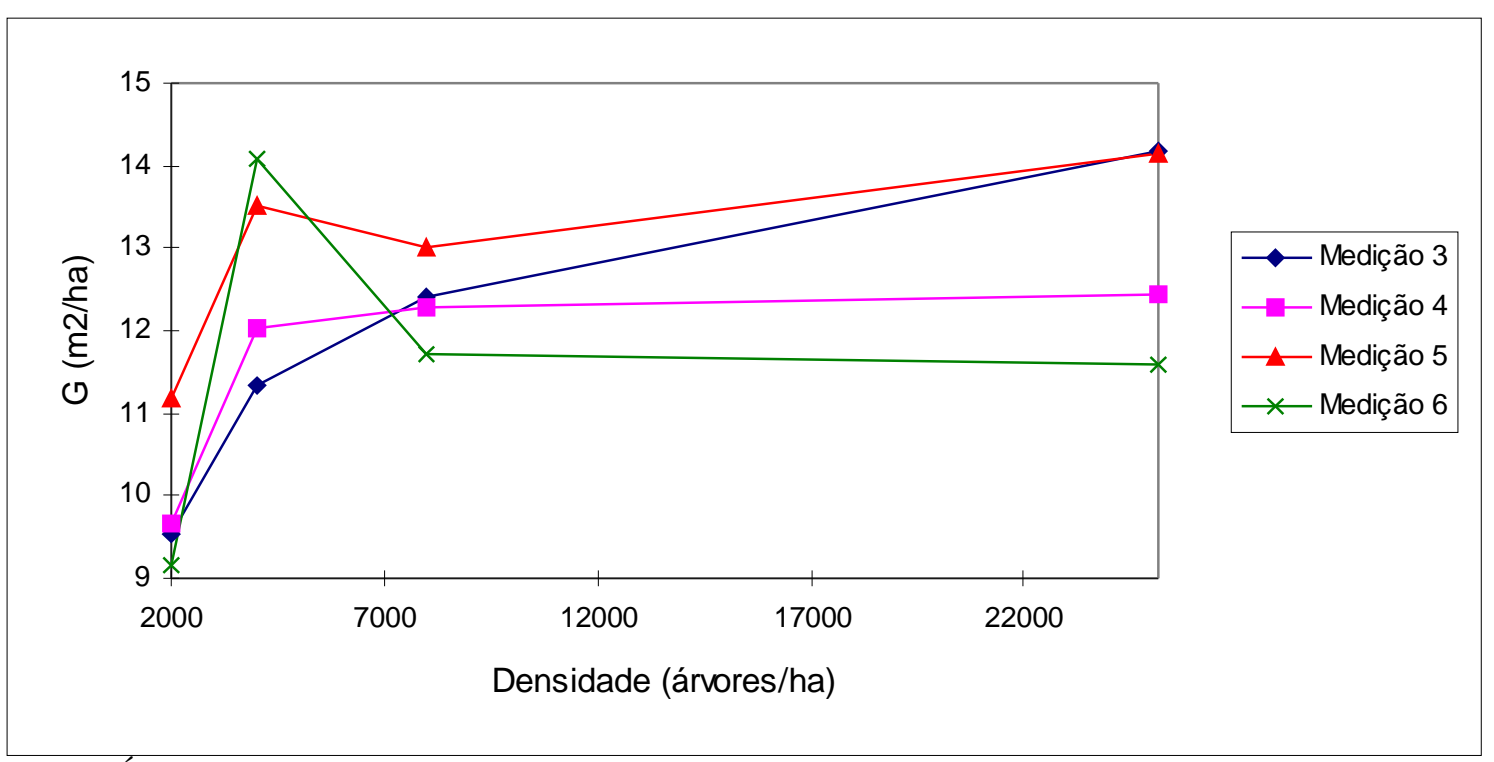

Figura 5: Área basal em função da densidade inicial. 


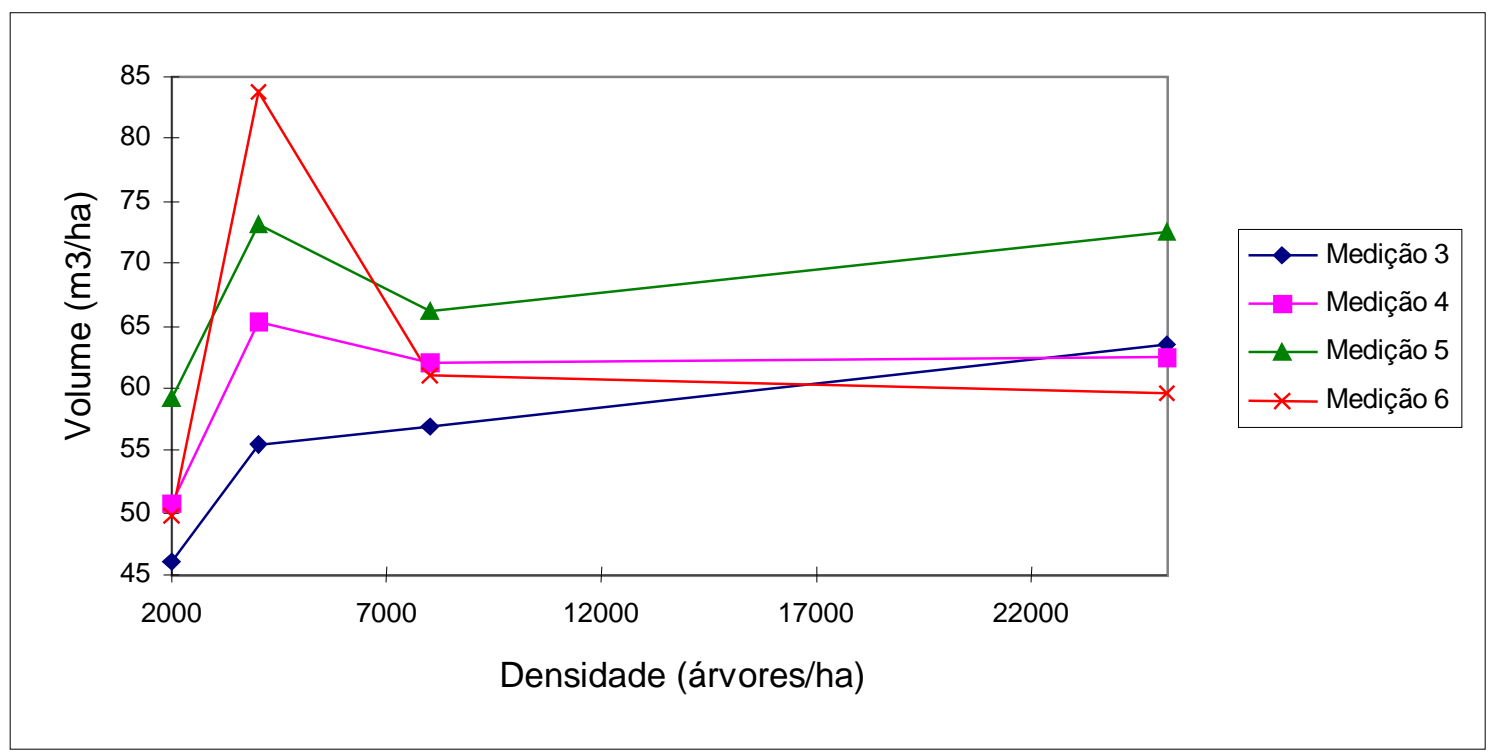

Figura 6: Volume/ha em função da densidade inicial

Ao contrário das demais variáveis, a grande variação de valores dentro de cada tratamento impossibilita a modelagem de $\mathrm{V}$ e $\mathrm{G}$ em função da densidade inicial. A análise de tendências, assim, só pode ser feita com base nas Figuras 5 e 6 . De modo geral, espera-se, a partir da análise dessas figuras, maiores área basal e volume/ha para a densidade inicial de 4 mil plantas/ha, menores para 2 mil e valores parecidos para as testemunhas e parcelas com densidade inicial de $8 \mathrm{mil}$ plantas/ha, nas idades de seis a sete anos e meio.

\section{Efeito do sítio}

Para a variável área basal, os resultados da análise de variância mostraram não haver diferenças entre os blocos. Já para a variável volume/ha, a análise de variância apontou diferenças devidas aos blocos nas medições 3,4 e 5 . Fez-se a interpolação dos dados da mesma forma e os resultados dos testes de Tukey encontram-se na Tabela 8 . Os resultados do teste de Tukey comprovam o efeito dos blocos sobre o volume/ha, que pode ser observado na Figura 6.

Tabela 9: Média de volume por hectare dos blocos

\begin{tabular}{|c|c|c|c|c|c|c|c|}
\hline \multirow[b]{2}{*}{ Blocos } & \multicolumn{2}{|c|}{4 anos } & \multicolumn{2}{|c|}{5 anos } & \multicolumn{3}{|c|}{6,3 anos } \\
\hline & Média & & Média & & Média & & \\
\hline ADR & 44,04 & $\mathrm{a}$ & 47,83 & $\mathrm{a}$ & 57,91 & $a$ & \\
\hline BDR & 37,14 & $\mathrm{a}$ & 48,96 & $\mathrm{a}$ & 64,07 & & $b$ \\
\hline BS & 62,26 & $\mathrm{~b}$ & 58,36 & $\mathrm{a} \quad \mathrm{b}$ & 68,60 & & $\mathrm{~b}$ \\
\hline $\mathrm{CC}$ & 63,99 & b & 68,64 & $\mathrm{~b}$ & 81,25 & & $\mathrm{~b}$ \\
\hline AT & 66,68 & b & 71,56 & b & ----- & -- & \\
\hline
\end{tabular}

Letras iguais indicam grupos homogêneos pelo teste de Tukey ao nível de 5\% de

\section{CONCLUSÕES}

- Para produção volumétrica e em área basal o maior valor foi gerado pelo tratamento 2 (4 mil plantas/ha), nas últimas medições. Excluindo esse tratamento, a produção foi diretamente proporcional à densidade inicial.

- Os sítios não influenciaram a área basal/ha, em nenhuma idade de medição. $\mathrm{O}$ volume/ha, por sua vez, sofreu influência dos sítios até a idade de 6,3 anos.

- As diferenças geradas por diferentes densidades iniciais foram mais expressivas para o sítio de qualidade mais baixa, ou seja, quanto pior o sítio, mais importante foi o desbaste na produção do volume/ha. 


\section{BIBLIOGRAFIA CITADA}

AHRENS, S. Um modelo matemático para volumetria comercial de bracatinga (Mimosa scabrella Benth). In: SEMINÁRIO SOBRE ATUALIDADES PERSPECTIVAS FLORESTAIS "BRACATINGA UMA OPÇÃO PARA REFLORESTAMENTO" (4.: 1981: Curitiba). Anais... Colombo: EMBRAPA-CNPF, 1981. p. 77-89

BAGGIO, A.J.; GRAÇA, L. R.; OLIVEIRA, E.B. de. Plantio intercalar de bracatinga em áreas de cultivo agrícola. In: ENCONTRO BRASILEIRO DE ECONOMIA E PLANEJAMENTO FLORESTAL (2.:1991 : Curitiba). Anais... Colombo: EMBRAPACNPF, 1992. p.297-316

CARPANEZZI, O.T.B. Resultados preliminares das unidades de comprovação do sistema bracatinga. Curitiba: EMATER, 1989.

EMBRAPA. Centro Nacional de Pesquisa de Florestas (Curitiba, PR). Manual técnico da bracatinga (Mimosa scabrella Benth). Curitiba: EMBRAPA-CNPF.,1988. 70 p. (Série Documentos, n.20).

IAPAR. Cartas climáticas do Estado do Estado do Paraná 1994. Londrina, 1994. (IAPAR. Documento, 18).

LAURENT, J.M.E. et al. Melhoramento do sistema agroflorestal da bracatinga. Curitiba: Projeto FAO-GCP/BRA/025/FRA, 1990.

LORENZI, H. Árvores brasileiras: manual de identificação e cultivo de plantas arbóreas nativas do Brasil. Nova Odessa, SP: Plantarum, 1992.

MACHADO, S.A.; OLIVEIRA, E.B. de; CARPANEZZI, A.A.; BARTOSZECK, A.C.P.S. Classificação de sítio para bracatingais na Região Metropolitana de Curitiba. Boletim de Pesquisa Florestal, Colombo, PR, v.35, 21-37, 1997.

ROCHADELLI, R. Contribuição sócioeconômica da bracatinga (Mimosa scabrella Bentham) na Região Metropolitana de Curitiba-Norte (RMC-N). Curitiba, 1997. Dissertação (Mestrado em Engenharia Florestal) - Setor de Ciências Agrárias, Universidade Federal do Paraná.
TONON, A.E.N. Efeitos da densidade inicial e do sítio sobre o crescimento e a produção de bracatingais da região metropolitana de Curitiba. Curitiba, 1998. Dissertação (Mestrado em Engenharia Florestal) - Setor de Ciências Agrárias, Universidade Federal do Paraná. 